\title{
Review \\ Role of Stress-Related Dopamine Transmission in Building and Maintaining a Protective Cognitive Reserve
}

\author{
Simona Cabib ${ }^{1,2, *(\mathbb{D})}$, Claudio Latagliata ${ }^{1}$ and Cristina Orsini ${ }^{2}$ (D) \\ 1 Department of Experimental Neurosciences, IRCCS Fondazione Santa Lucia, 00179 Roma, Italy; \\ claudio.latagliata@gmail.com \\ 2 Department of Psychology, Sapienza University of Rome, 00185 Roma, Italy; cristina.orsini@uniroma1.it \\ * Correspondence: simona.cabib@uniroma1.it
}

Citation: Cabib, S.; Latagliata, C.; Orsini, C. Role of Stress-Related Dopamine Transmission in Building and Maintaining a Protective Cognitive Reserve. Brain Sci. 2022, 12, 246. https://doi.org/10.3390/ brainsci12020246

Academic Editors: Suelen Boschen, Paolo D'Aquila and Deranda Lester

Received: 25 January 2022

Accepted: 8 February 2022

Published: 11 February 2022

Publisher's Note: MDPI stays neutral with regard to jurisdictional claims in published maps and institutional affiliations.

Copyright: (C) 2022 by the authors. Licensee MDPI, Basel, Switzerland. This article is an open access article distributed under the terms and conditions of the Creative Commons Attribution (CC BY) license (https:// creativecommons.org/licenses/by/ $4.0 /)$.

\begin{abstract}
This short review presents the hypothesis that stress-dependent dopamine (DA) transmission contributes to developing and maintaining the brain network supporting a cognitive reserve. Research has shown that people with a greater cognitive reserve are better able to avoid symptoms of degenerative brain changes. The paper will review evidence that: (1) successful adaptation to stressors involves development and stabilization of effective but flexible coping strategies; (2) this process requires dynamic reorganization of functional networks in the adult brain; (3) DA transmission is amongst the principal mediators of this process; (4) age- and disease-dependent cognitive impairment is associated with dysfunctional connectivity both between and within these same networks as well as with reduced DA transmission.
\end{abstract}

Keywords: avoidance; cognitive reserve; connectivity; controllability; coping; dopamine; large-scale brain networks

\section{Introduction}

The concept of cognitive reserve (CR) was developed to explain why brain damage does not always predict the severity of cognitive dysfunctions. It was associated with a history of positive life experiences (higher education and work milestones, active and rewarding lifestyles) and IQ. Hence, these factors are considered proxies and used as a measure of $C R$ in the absence of a validated marker. CR proxies are associated with a reduced risk of cognitive decline in normal aging and dementia [1-3]. Moreover, Alzheimer's disease (AD) patients with CR proxies can show more advanced AD-type neuropathology but comparable clinical severity of cognitive impairment than those without CR proxies [2,4]. Studies have reported similar findings in different neurodegenerative diseases such as multiple sclerosis [5], Parkinson's disease [6], and schizophrenia [7]. Therefore, there is an increasing interest in developing interventions capable of fostering CR in the treatment of cognitive decline. This goal requires identifying neural processes and mechanisms involved in developing and maintaining this phenotype [8].

It has been proposed that CR involves efficient and flexible utilization of different brain networks. An authoritative CR definition posits that proxies " ... result in individual differences in the flexibility and adaptability of brain networks that may allow some people to cope better than others with age- or dementia-related brain changes" [1]. This definition could well refer to the outcome of a history of successful coping with acute stressful experiences. Indeed, stressors are rarely traumatic; they are primarily changes in lifestyles that require the adaptation of behavioral, affective, and cognitive strategies [9]. Thus, marriage and personal achievement score 50 and 25/100, respectively, on a standard stress severity scale $[10,11]$. Moreover, human and animal studies have demonstrated that whereas traumatic, repeated, or chronic uncontrollable/unavoidable stress experiences foster dysfunctional adaptation, successful coping experiences make adults resilient to 
further stress. Being stress-resilient does not mean being insensitive to stressful events but capable of successfully adapting to the specific challenge encountered [12-17].

Results from animal or human studies also support the prominent role of dopamine (DA) transmission in developing and stabilizing successful coping strategies [12,18-20]. Conversely, reduced DA transmission has been associated with depressive symptoms, including anhedonia and apathy, which characterize both AD and frontotemporal dementia [21-25]. Moreover, data collected in AD patients and animal models of AD support impaired DA transmission in cognitive impairment, and age-related decline in striatal DA has been associated with the cognitive decline seen in normal aging [26-29]. Finally, evidence from genetic AD models indicates reduced DA availability in the limbic systems that largely precedes the development of the classical AD profile [30].

This brief review proposes a role of DA transmission associated with successful stress coping in fostering the brain network needed to support CR. Therefore, it will be focused on the dynamic of coping with novel stress, the responses and plasticity of brain circuits engaged by successful coping with stressful experiences, and the ability of DA to drive, guide, and control the reorganization of these circuits. Moreover, the evidence discussed will mostly come from research in animal models because of the difficulties of measuring changes in DA neurotransmission in human subjects and the advantage of testing causal influences of brain DA transmission on behavioral phenotypes offered by animal models.

\section{Learning to Cope with Stress}

Organisms behaviorally deal with stressful events through coping strategies that terminate the physiological defensive responses needed but are expensive and dangerous in the long run (allostatic overload) [31]. Thus, most coping strategies aim to remove or avoid the source of stress, and they are successful when stressors are susceptible to the organisms' actions (removable, escapable/avoidable, controllable). Nonetheless, some stressors cannot be removed or escaped, such as losing a loved one. In these cases, coping strategies aim to control the emotional arousal responsible for maintaining physiological stress responses $[9,32]$.

Studies in animal models investigate controlling stress severity and duration and the interaction between stressors and individuals. Results obtained by these studies indicate that coping strategies are developed through trial and error and stabilized through learningrelated processes. Virtually all the aversively motivated learning tasks used in animal research are stressful situations that can be escaped, avoided, or controlled by specific coping strategies. Rodents learn to escape from a water maze by swimming toward a hidden platform that can be found in specific locations and learn to avoid a shock by performing specific actions when a conditioned stimulus (CS) predicts its arrival. These are strategies rather than reactions to aversive stimuli. Indeed, finding a hidden platform may require the use of complex cognitive abilities [33], while learning to avoid a shock predicted by a CS requires inhibition of the freezing response, an evolutionary preserved defensive reaction toward potential threats, as well as control over the impulse to escape before CS presentation [34-36].

Coping strategies must be flexible to adapt to new experiences. Thus, freezing is usually the immediate response to an unpredicted change in the environment and allows the organism to evaluate impending threats while reducing the risks of being detected [37]. Escape is the subsequent reaction because it requires the appraisal of actual risk and inhibition of the freezing response [17]. However, organisms need to inhibit both of these reactive coping responses to develop proactive strategies that are adaptive in the specific context [38]. Finally, findings from animal studies indicate that adapting to a novel stressor requires extinction processes that involve learning to inhibit the expression of previously acquired successful strategies appraised as ineffective in the new context [39].

The experience of successful coping fosters the learning of a specific response and protects the organism from dysfunctional outcomes of subsequent encounters with pathogenic stressors. Rats that learn to temporarily control a shock experience by an instrumental 
escape response (wheel turning) do not show the behavioral and neurochemical effects of a social defeat experience occurring seven days later in a different context [16]. These findings were obtained with the so-called 'triadic' protocol developed by S.F. Maier $[16,40]$. In this protocol, pairs of rats are exposed to tail-shocks delivered at random intervals, while control rats are exposed to the apparatus without receiving shocks. Only one rat can temporarily block the shock delivery (exposed to escapable stress: ES) for both members of a shocked couple. Thus, the yoked rats (exposed to inescapable stress: IS) share with the ES rats the experience of the physical aspects of the stressor (intensity, duration, temporal distributions) but not the experience of successfully controlling it [16,40]. Results obtained with this protocol demonstrated the expression of the behavioral indices of a severe anxiety-depression syndrome by IS but not by ES rats. Moreover, whereas ES rats readily and persistently extinguished a newly acquired conditioned freezing when the CS was disassociated from the aversive experience, the IS rats acquired conditioned freezing as an inflexible and relapsing response. Finally, implementing a triadic-like protocol in human experiments (using a loud noise as a stressor) yielded similar findings [40].

The reviewed evidence supports the conclusion that the experience of successful coping with stressful events fosters the ability to develop flexible strategies and protect organisms against the risk of developing phenotypes associated with anxiety and depression through subsequent interactions with uncontrollable/unavoidable stressors.

\section{The Neurocircuitry of Stress Coping}

Findings from studies in animal models indicate that brain responses to a novel stressor allow the organism to stabilize the coping strategy that is most effective for that situation. Hormonal and neurochemical stress responses engage different brain networks by sequentially activating and inhibiting the different loops connecting prefrontal cortices with limbic and striatal targets. The outcomes of the attempts to cope with the stressful experience determine the dynamic of this process $[15,41]$.

The amygdala orchestrates long-term learning stabilization (memory consolidation) under emotional arousal, by modulating the mnemonic activity and synaptic plasticity in several brain regions [42]. Noradrenergic stimulation of the amygdala, typically fostered by arousing experiences, enhances the consolidation of both striatum-dependent and hippocampus-dependent memory. Moreover, noradrenergic activation in the basolateral amygdala (BLA) is required for stress hormones (glucocorticoids) to influence memory processing dependent on prelimbic cortex (PL) interactions with the anterior insular cortex (aIC) and dorsal hippocampus [43]. On the other hand, partially overlapping competitive circuits allow for flexible adaptation of acquired responses to the ongoing experience. A circuit connecting the infralimbic cortex (IL) with a GABAergic nucleus of the amygdala supports the extinction of a consolidated freezing response when the CS ceases to predict the aversive experience, a process moderated by the IC [44,45]. Moreover, a circuit connecting the PL with the ventral striatum through the BLA allows for escape/avoidance responses to overcome freezing when needed $[36,38]$.

As discussed, learning to successfully cope with adverse experiences fosters resilience to subsequent stress experiences. Thus, rats who have learned to stop shock delivery temporarily (ES rats) are protected against the dysfunctional sequalae fostered by the stressor and by subsequent experiences of uncontrollable stress. A PL-centered circuit supports these protective effects [16,46]. Indeed, a PL connection with the dorsal raphe nucleus (DRN) was shown to inhibit serotonin (5-HT) release from local neurons and prevent the dysfunctional outcomes of the stressful experience in ES. Moreover, a PL connection with the dorsomedial striatum (DMS) is responsible for the appraisal of the situation as 'controllable', which fosters structural plasticity (increase in dendritic spines) in the PL. This neuroplastic event, in turn, is required for the PL-DMS circuit to be activated in response to subsequent uncontrollable stressors [47]. Finally, stressors used to model psychiatric disturbances in experimental animals foster a decrease rather than an increase in structural connectivity within the PL [48-50]. 
Human neuroimaging data collected in recent years indicate that exposure to an experimental stressor fosters a reallocation of resources to a large-scale neurocognitive network known as the salience network (SN). Large-scale networks consist of self-organized co-activation of brain areas. They are identified through resting-state functional magnetic resonance imaging by correlating fluctuations in the blood oxygen signal in different brain areas. According to the results of the meta-analyses of functional neuroimaging data, SN nodes respond consistently to different salient stimuli, including aversive material, conditioned stimuli, and pain. Thus, the network is proposed to play a crucial role in identifying the most relevant internal and external stimuli to guide behavior appropriately [51-53]. Although the brain areas included in a specific network can differ slightly, due to the rapid increase in data that characterizes this area of research, major nodes of the SN network are the dorsal anterior Cingulate Cortex (daCC), the aIC, the striatum, the amygdala, and the DAergic brainstem nuclei [53-55]. Together, these structures complete a discrete cortico-striatal-thalamic-cortical loop evident at functional and structural levels [55,56]. Finally, substantial evidence indicates that human aCC and rodents PL play the same role in supporting threat responses and connect with the same limbic/striatal areas [57]. Therefore, the SN encompasses the circuits that mediate the development and stabilization of coping strategies in animal models.

$\mathrm{SN}$ is only one of the identified large-scale networks. Still, it appears to dynamically control the communication between the default-mode (DMN) and the central-executive (CEN) networks in both young and elderly healthy subjects [58]. DMN network is more activated during internally directed cognitive activities, such as self-monitoring and social functions. In contrast, CEN seems to be more activated by externally controlled higher-order cognitive functions, such as attention, working memory, and decision-making. Evidence supports the hypothesis that functional coupling between the large-scale brain networks is essential for successful cognition and coping across health and disease [54,58-61]. Moreover, a pivotal role for the activity of DMN and $\mathrm{SN}$ in individual coping styles has been reported [62]. Most importantly, for the topic of the present review, higher connectivity between major networks in the brain is associated with an effective CR in Alzheimer's disease and very high cognitive performance in healthy aging [63-66]. Finally, although most of these reports are based on functional connectivity data, there is evidence of structural effects of CR proxies [3,65,67].

Together, these considerations support the conclusion that coping with acute stress is mediated by a brain network centered around PL and IC that engages the amygdala, the striatum, and DA transmission. Moreover, stabilization of flexible adaptive coping strategies requires neuroplasticity within specific nodes of these circuits. On the other hand, data from human studies indicate that SN, a large-scale network including daCC, aIC, the amygdala, the striatum, and the brain DA systems, is engaged by stress experiences and coping. Finally, functional and structural plasticity within and between the SN and other primary brain networks exert protection against cognitive deterioration fostered by aging ad disease.

\section{Dopamine}

Neural responses to environmental changes enable organisms to rapidly detect threats, respond adequately, restore homeostasis through successful coping, and better prepare for future challenges. Stress-sensitive hormones and neurotransmitters are dynamically activated and inhibited to modulate the neural excitability of different brain circuits. This complex response develops according to a highly preserved pattern across species and is sensitive to the outcomes of the ongoing interaction between the organism and the stressor. There are several informative reviews on stress hormones, norepinephrine (NE), 5-HT, and their effects on brain functioning and plasticity [20,68-73]. Therefore, the present review focuses on DA transmission.

The DA circuit involved in successful coping with acute stress is the mesocorticolimbic system made up by ventral tegmental area (VTA) DA neurons projecting to the PL, the 
amygdala, the ventral striatum (NAc), and the hippocampus. A recent review defined the role of the mesocorticolimbic circuitry: " ... as a hub linking circuits involved in the emotional-motivational appraisal of salient information with networks underlying executive functioning" [20]. Indeed, the mesocorticolimbic circuit includes core regions of the SN, and it is in the position to engage the dorsal striatum through a dynamic 'spiraling' connection with the substantia nigra [74], the major source of striatal DA (Figure 1). Data collected in animal models point to a rapid but temporary increase in extracellular DA in PL, amygdala, and NAc in response to novel stress [19,75-77]. The NAc DA response to novel stressors is dependent on increased NE transmission in the PL and is constrained by DA transmission in the same brain area [19,78-81]. DA transmission in the NAc supports active coping by stimulating DA receptors of the D2 type $[9,19,82]$ and is dependent on the expectancy of successful active coping. Indeed, during the experience of a novel stressful situation as inescapable and uncontrollable, DA release in the NAc is progressively inhibited by a sharp reduction in NE and a parallel increase in DA in the PL [19].

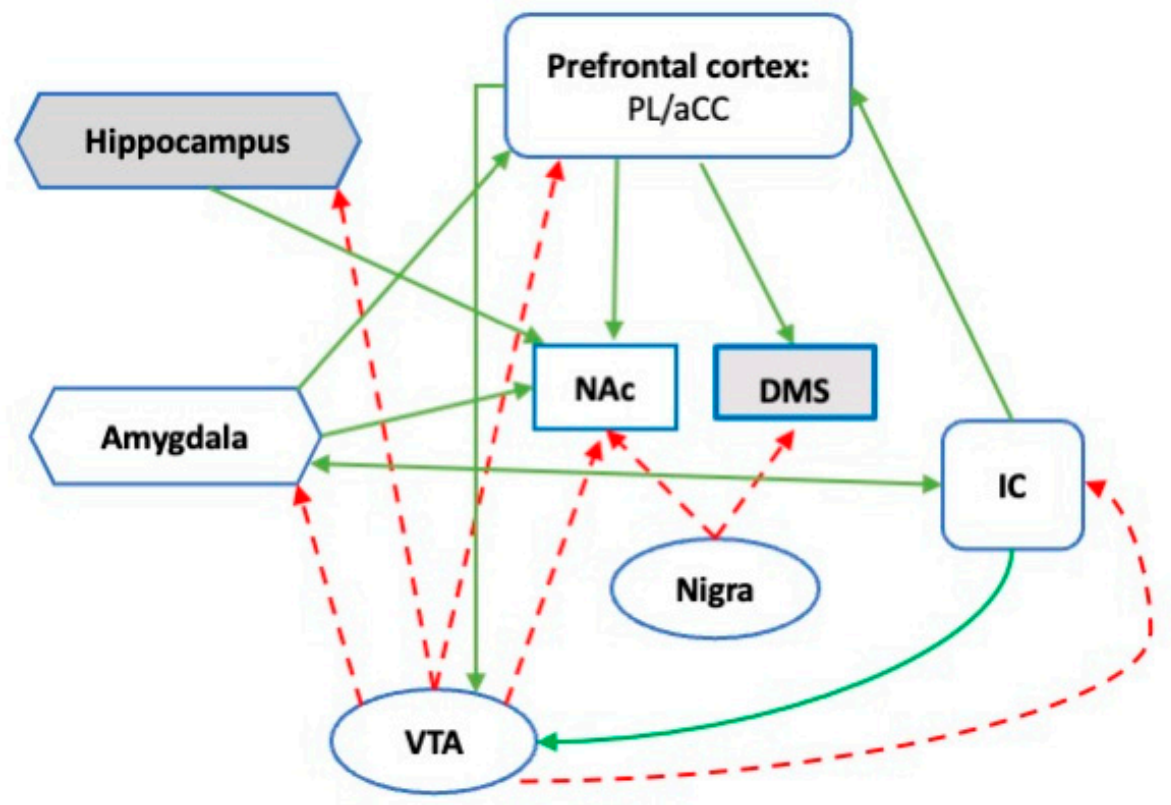

Figure 1. Schematic representation of the mesocorticolimbic DA system associated with stress coping. Dotted lines indicate DA afferences; solid lines indicate functional connectivity; white-filled areas are part of the SN in humans and rodents [53]. PL prelimbic cortex; aCC: Anterior cingulate cortex; IC: Insula cortex; NAc: Nucleus accumbens/ventral striatum; DMS: Dorsomedial striatum; Nigra: Substantia nigra pars compacta; VTA: Ventral tegmental area.

One of the hypothesized mechanisms by which brain DA acts is in mediating the dynamic balance between processes of "flexible updating and cognitive stabilization" [83]. As discussed, a PL-DMS circuit is engaged by the appraisal of stress controllability. Inactivation of each brain area does not influence either the expression or the acquisition of the specific coping response used to control the stressor. Instead, connectivity between PL and DMS is required for the protective effects of the previous experience of control against dysfunctional outcomes of subsequent inescapable-uncontrollable stressors [16]. A PL-DMS connection is also involved in the acquisition of positively valued goal-directed instrumental actions, which flexibly adapt to changes in the value of the goal. Instead, connectivity between motor cortices and the dorsolateral striatum (DLS) is required to acquire a habitual instrumental response elicited by conditioned stimuli regardless of the goal value [84]. All instrumental responses are acquired in parallel by the two circuits, which then compete to control the expression of instrumental responses. DA transmission in DMS or DLS will determine whether the organism expresses the acquired goal-directed or habitual response [84]. It is thus possible that rats exposed to controllable stress engage 
the circuit responsible for habitual behavior to express a specific escape response but engage the circuit responsible for goal-directed behavior to adapt to novel stressful conditions. In line with this hypothesis, six weeks of voluntary wheel running, which protects rats against the adverse effects of uncontrollable stress as the acute experience of control does, were shown to significantly enhance DA release induced by an uncontrollable shock in the DMS but not in DLS [85].

An acute stress experience or the administration of anxiogenic compounds increases DA output in the PL/IL area of Roman high-avoidance (RHA/Verh) but not of Roman low-avoidance rats (RLA/Verh). RHA/Verh display robust and long-lasting active coping with novel stressors, whereas RLA/Verh rats show frequent freezing that interferes with acquiring the active avoidance response [86]. DA transmission in the PL does not mediate the acquisition of a positively reinforced instrumental response, but it is necessary for learning about action-outcome associations [50]. Thus, DA transmission within the PL could guide the choice of the most effective coping strategies in novel stressful situations. In line with this hypothesis, a specific PL-DMS pathway is involved in decision-making about motivationally conflicting options [87].

Rats with experience of control over a stressor show increased dendritic spines within PL [47]. As discussed, experimental stressful experiences used to reproduce dysfunctional phenotypes in animal models foster increased structural neuroplasticity in striatal/limbic targets but reduced plasticity in PL $[48-50,88]$ and the PL-DMS circuit is disrupted by the experience of these stressors [89]. Structural plasticity in the adult brain relies on the experience-dependent proliferation and pruning of dendritic spines within specific networks, leading to reorganization of connectivity between neuronal populations. DA is required for glutamate-induced spinogenesis and exerts dichotomous effects on neurons expressing the D1 or D2 receptor subtypes so that they store memories of reward and reward omission, respectively, through cell-type-specific spine enlargement [90,91]. Finally, reduced DA availability due to degeneration of DA cells interferes with spinogenesis while increasing pruning [92].

Moreover, there is strong evidence that DA transmission modulates SN connectivity [93-95]. DA modulates aCC activity during executive tasks and the synaptic availability of DA may be directly related to efficient IC function. On the other hand, a high correlation between the binding of the D2/D3 ligand [18F]-fallypride and grey matter density has been observed in the aCC, IC, and midbrain, suggesting that reduced grey matter observed in the SN of schizophrenics is directly associated with DA deficits [95]. Moreover, DA synthesis capacity has been recently associated with greater SN connectivity, particularly in brain regions that act as information-processing hubs [94] and there is strong evidence for VTA functional connectivity with the posterior cingulate/precuneus, a central hub node of the DMN [96]. On the other hand, progressive depletion of striatal DA is the hallmark of Parkinson's disease (PD). Around 30\% of PD patients present cognitive deficits long before the appearance of classic motor symptoms and evidence from clinical and preclinical studies on cognitive deficits in PD points to a role of reduced striatal DA availability [6,97]. There is strong evidence that reduced DA availability in the ventral striatum (NAc) precedes typical motor deficits in PD and several studies found a reduced connectivity between the aCC and the ventral striatum [98]. Finally, PD patients with mild cognitive impairment, who are susceptible to developing dementia, are characterized by severe DA depletion in the associative striatum and reduced D2 receptor availability in the IC [99]. These findings seem coherent with the dynamic relationship between PL and NAc DA observed in stressed animals and bridge dysfunctional connectivity within SN and between large brain networks with cognitive impairment and reduced DA transmission.

Together, the discussed evidence points to a significant role of DA transmission in cortical, limbic, and striatal nodes in the immediate and long-term adaptive effects of successful coping with stress challenges. Moreover, the reviewed evidence suggests that DA exerts this role by modulating both functional and structural brain connectivity within the $\mathrm{SN}$ and supports a strong influence of this modulation on cognitive capacity. 


\section{Conclusions}

This brief review discussed evidence of an overlap between brain circuitry supporting the development and stabilization of adaptive stress coping strategies and cognitive functioning in aging and disease. Moreover, we pointed to a significant moderating role of DA transmission in specific nodes of the SN in circuital functioning and plasticity in the adult brain. Based on these considerations, it is reasonable to hypothesize that experiences of successful coping with life events, through DA transmission-induced modulation of brain functional and structural connectivity, contribute to establishing a rich CR. Instead, reduced brain DA availability, due to genetic predisposition or to a history of uncontrollable/unavoidable experiences, can undermine the development and maintenance of CR, leading to more severe and rapid cognitive deterioration in response to neurodegeneration. Finally, the proposed hypothesis opens new opportunities to translational research by overcoming the problems of reproducing classic CR proxies in animal models.

Author Contributions: S.C. proposed the topic and prepared a first sketch of the manuscript; S.C., C.L. and C.O. discussed and equally contributed to the submitted versions of the paper. All authors have read and agreed to the published version of the manuscript.

Funding: This work was founded by Italian Ministry of Health: NoGR 201812365991.

Data Availability Statement: Not applicable.

Conflicts of Interest: The authors declare no conflict of interest.

\section{References}

1. Stern, Y. What is cognitive reserve? Theory and research application of the reserve concept. J. Int. Neuropsychol. Soc. 2002, 8, 448-460. [CrossRef] [PubMed]

2. Stern, Y. How Can Cognitive Reserve Promote Cognitive and Neurobehavioral Health? Arch. Clin. Neuropsychol. 2021, 36, 1291-1295. [CrossRef] [PubMed]

3. Pettigrew, C.; Soldan, A. Defining Cognitive Reserve and Implications for Cognitive Aging. Curr. Neurol. Neurosci. Rep. 2019, 19, 1-12. [CrossRef] [PubMed]

4. Cabeza, R.; Albert, M.; Belleville, S.; Craik, F.I.M.; Duarte, A.; Grady, C.L.; Lindenberger, U.; Nyberg, L.; Park, D.C.; Reuter-Lorenz, P.A.; et al. Maintenance, reserve and compensation: The cognitive neuroscience of healthy ageing. Nat. Rev. Neurosci. 2018, 19, 701-710. [CrossRef]

5. Estrada-Lopez, M.; Garcia-Martin, S.; Canton-Mayo, I. Cognitive Dysfunction in Multiple Sclerosis: Educational Level as a Protective Factor. Neurol. Int. 2021, 13, 335-342. [CrossRef]

6. Loftus, A.M.; Gasson, N.; Lopez, N.; Sellner, M.; Reid, C.; Cocks, N.; Lawrence, B.J. Cognitive Reserve, Executive Function, and Memory in Parkinson's Disease. Brain. Sci. 2021, 11, 992. [CrossRef]

7. Herrero, P.; Contador, I.; Stern, Y.; Fernandez-Calvo, B.; Sanchez, A.; Ramos, F. Influence of cognitive reserve in schizophrenia: A systematic review. Neurosci. Biobehav. Rev. 2020, 108, 149-159. [CrossRef]

8. Perneczky, R.; Kempermann, G.; Korczyn, A.D.; Matthews, F.E.; Ikram, M.A.; Scarmeas, N.; Chetelat, G.; Stern, Y.; Ewers, $\mathrm{M}$. Translational research on reserve against neurodegenerative disease: Consensus report of the International Conference on Cognitive Reserve in the Dementias and the Alzheimer's Association Reserve, Resilience and Protective Factors Professional Interest Area working groups. BMC Med. 2019, 17, 47.

9. Ventura, R.; Cabib, S.; Babicola, L.; Andolina, D.; Di Segni, M.; Orsini, C. Interactions Between Experience, Genotype and Sex in the Development of Individual Coping Strategies. Front. Behav. Neurosci. 2021, 15, 785739. [CrossRef]

10. Holmes, T.H.; Rahe, R.H. The Social Readjustment Rating Scale. J. Psychosom. Res. 1967, 11, 213-218. [CrossRef]

11. Scully, J.; Tosi, H.; Banning, K. Life Event Checklists: Revisiting the Social Readjustment Rating Scale after 30 Years. Educ. Psychol. Meas. 2000, 60, 864-876. [CrossRef]

12. Charney, D.S. Psychobiological mechanisms of resilience and vulnerability: Implications for successful adaptation to extreme stress. Am. J. Psychiatry 2004, 161, 195-216. [CrossRef] [PubMed]

13. Daskalakis, N.P.; Bagot, R.C.; Parker, K.J.; Vinkers, C.H.; de Kloet, E.R. The three-hit concept of vulnerability and resilience: Toward understanding adaptation to early-life adversity outcome. Psychoneuroendocrinology 2013, 38, 1858-1873. [CrossRef] [PubMed]

14. Taylor, A.E.; Stanton, A.L. Coping resources, coping processes, and mental health. Annu. Rev. Clin. Psychol. 2007, 3, 377-401. [CrossRef]

15. Cabib, S.; Campus, P.; Conversi, D.; Orsini, C.; Puglisi-Allegra, S. Functional and Dysfunctional Neuroplasticity in Learning to Cope with Stress. Brain. Sci. 2020, 10, 127. [CrossRef]

16. Maier, S.F. Behavioral control blunts reactions to contemporaneous and future adverse events: Medial prefrontal cortex plasticity and a corticostriatal network. Neurobiol. Stress 2015, 1, 12-22. [CrossRef] 
17. Cabib, S.; Campus, P.; Latagliata, E.C.; Orsini, C.; Tarmati, V. Repetitive and Inflexible Active Coping and Addiction-like Neuroplasticity in Stressed Mice of a Helplessness-Resistant Inbred Strain. Behav. Sci. 2021, 11, 174. [CrossRef]

18. Southwick, S.M.; Vythilingam, M.; Charney, D.S. The psychobiology of depressione and resilience to stress: Implications for Prevention and Treatment $£^{\mathrm{TM}}$. Annu. Rev. Clin. Psychol. 2005, 1, 255-291. [CrossRef]

19. Cabib, S.; Puglisi-Allegra, S. The mesoaccumbens dopamine in coping with stress. Neurosci. Biobehav. Rev. 2012, 36, 79-89. [CrossRef]

20. Douma, E.H.; de Kloet, E.R. Stress-induced plasticity and functioning of ventral tegmental dopamine neurons. Neurosci. Biobehav. Rev. 2020, 108, 48-77. [CrossRef]

21. Delva, N.C.; Stanwood, G.D. Dysregulation of brain dopamine systems in major depressive disorder. Exp. Biol. Med. 2021, 246, 1084-1093. [CrossRef] [PubMed]

22. Goldstein Ferber, S.; Weller, A.; Yadid, G.; Friedman, A. Discovering the Lost Reward: Critical Locations for Endocannabinoid Modulation of the Cortico-Striatal Loop That Are Implicated in Major Depression. Int. J. Mol. Sci. 2021, $22,1867$. [CrossRef] [PubMed]

23. Wang, S.; Leri, F.; Rizvi, S.J. Anhedonia as a central factor in depression: Neural mechanisms revealed from preclinical to clinical evidence. Prog. Neuropsychopharmacol. Biol. Psychiatry 2021, 110, 110289. [CrossRef] [PubMed]

24. McLaurin, K.A.; Harris, M.; Madormo, V.; Harrod, S.B.; Mactutus, C.F.; Booze, R.M. HIV-Associated Apathy /Depression and Neurocognitive Impairments Reflect Persistent Dopamine Deficits. Cells 2021, 10, 2158. [CrossRef] [PubMed]

25. Noworyta, K.; Cieslik, A.; Rygula, R. Neuromolecular Underpinnings of Negative Cognitive Bias in Depression. Cells 2021, 10, 3157. [CrossRef]

26. Backman, L.; Lindenberger, U.; Li, S.C.; Nyberg, L. Linking cognitive aging to alterations in dopamine neurotransmitter functioning: Recent data and future avenues. Neurosci. Biobehav. Rev. 2010, 34, 670-677. [CrossRef]

27. Pan, X.; Kaminga, A.C.; Wen, S.W.; Wu, X.; Acheampong, K.; Liu, A. Dopamine and Dopamine Receptors in Alzheimer's Disease: A Systematic Review and Network Meta-Analysis. Front. Aging Neurosci. 2019, 11, 175. [CrossRef]

28. D'Amelio, M.; Puglisi-Allegra, S.; Mercuri, N. The role of dopaminergic midbrain in Alzheimer's disease: Translating basic science into clinical practice. Pharmacol. Res. 2018, 130, 414-419. [CrossRef]

29. Koch, G.; Di Lorenzo, F.; Bonni, S.; Giacobbe, V.; Bozzali, M.; Caltagirone, C.; Martorana, A. Dopaminergic modulation of cortical plasticity in Alzheimer's disease patients. Neuropsychopharmacology 2014, 39, 2654-2661. [CrossRef]

30. Nobili, A.; Latagliata, E.C.; Viscomi, M.T.; Cavallucci, V.; Cutuli, D.; Giacovazzo, G.; Krashia, P.; Rizzo, F.R.; Marino, R.; Federici, M.; et al. Dopamine neuronal loss contributes to memory and reward dysfunction in a model of Alzheimer's disease. Nat. Commun. 2017, 8, 14727. [CrossRef]

31. McEwen, B.S.; Gianaros, P.J. Stress- and allostasis-induced brain plasticity. Annu. Rev. Med. 2011, 62, 431-445. [CrossRef] [PubMed]

32. de Kloet, E.R.; Molendijk, M.L. Coping with the Forced Swim Stressor: Towards Understanding an Adaptive Mechanism. Neural. Plast. 2016, 2016, 6503162. [CrossRef] [PubMed]

33. Vorhees, C.V.; Williams, M.T. Assessing spatial learning and memory in rodents. ILAR J. 2014, 55, 310-332. [CrossRef] [PubMed]

34. Piantadosi, P.T.; Yeates, D.C.M.; Floresco, S.B. Cooperative and dissociable involvement of the nucleus accumbens core and shell in the promotion and inhibition of actions during active and inhibitory avoidance. Neuropharmacology 2018, 138, 57-71. [CrossRef] [PubMed]

35. Wenzel, J.M.; Oleson, E.B.; Gove, W.N.; Cole, A.B.; Gyawali, U.; Dantrassy, H.M.; Bluett, R.J.; Dryanovski, D.I.; Stuber, G.D.; Deisseroth, K.; et al. Phasic Dopamine Signals in the Nucleus Accumbens that Cause Active Avoidance Require Endocannabinoid Mobilization in the Midbrain. Curr. Biol. 2018, 28, 1392-1404.e1395. [CrossRef]

36. Diehl, M.M.; Bravo-Rivera, C.; Quirk, G.J. The study of active avoidance: A platform for discussion. Neurosci. Biobehav. Rev. 2019, 107, 229-237. [CrossRef]

37. Roelofs, K. Freeze for action: Neurobiological mechanisms in animal and human freezing. Philos. Trans. R. Soc. Lond. B Biol. Sci. 2017, 372, 20160206. [CrossRef]

38. Boeke, E.A.; Moscarello, J.M.; LeDoux, J.E.; Phelps, E.A.; Hartley, C.A. Active Avoidance: Neural Mechanisms and Attenuation of Pavlovian Conditioned Responding. J. Neurosci. 2017, 37, 4808-4818. [CrossRef]

39. Moscarello, J.M.; Maren, S. Flexibility in the face of fear: Hippocampal-prefrontal regulation of fear and avoidance. Curr. Opin. Behav. Sci. 2018, 19, 44-49. [CrossRef]

40. Maier, S.F.; Seligman, M.E. Learned helplessness at fifty: Insights from neuroscience. Psychol. Rev. 2016, 123, 349-367. [CrossRef]

41. Cabib, S.; Campus, P.; Colelli, V. Learning to cope with stress: Psychobiological mechanisms of stress resilience. Rev. Neurosci. 2012, 23, 659-672. [CrossRef] [PubMed]

42. Roozendaal, B.; McEwen, B.S.; Chattarji, S. Stress, memory and the amygdala. Nat. Rev. Neurosci. 2009, 10, 423-433. [CrossRef] [PubMed]

43. Barsegyan, A.; Mirone, G.; Ronzoni, G.; Guo, C.; Song, Q.; van Kuppeveld, D.; Schut, E.H.S.; Atsak, P.; Teurlings, S.; McGaugh, J.L.; et al. Glucocorticoid enhancement of recognition memory via basolateral amygdala-driven facilitation of prelimbic cortex interactions. Proc. Natl. Acad. Sci. USA 2019, 116, 7077-7082. [CrossRef] [PubMed]

44. Namkung, H.; Thomas, K.L.; Hall, J.; Sawa, A. Parsing neural circuits of fear learning and extinction across basic and clinical neuroscience: Towards better translation. Neurosci. Biobehav. Rev. 2021, 134, 104502. [CrossRef] [PubMed] 
45. Klein, A.S.; Dolensek, N.; Weiand, C.; Gogolla, N. Fear balance is maintained by bodily feedback to the insular cortex in mice. Science 2021, 374, 1010-1015. [CrossRef]

46. Maier, S.F.; Watkins, L.R. Role of the medial prefrontal cortex in coping and resilience. Brain. Res. 2010, 1355, 52-60. [CrossRef]

47. Baratta, M.V.; Gruene, T.M.; Dolzani, S.D.; Chun, L.E.; Maier, S.F.; Shansky, R.M. Controllable stress elicits circuit-specific patterns of prefrontal plasticity in males, but not females. Brain. Struct. Funct. 2019, 224, 1831-1843. [CrossRef]

48. Willner, P. The chronic mild stress (CMS) model of depression: History, evaluation and usage. Neurobiol. Stress. 2017, 6, 78-93. [CrossRef]

49. Dias-Ferreira, E.; Sousa, J.C.; Melo, I.; Morgado, P.; Mesquita, A.R.; Cerqueira, J.J.; Costa, R.M.; Sousa, N. Chronic stress causes frontostriatal reorganization and affects decision-making. Science 2009, 325, 621-625. [CrossRef]

50. Woon, E.P.; Sequeira, M.K.; Barbee, B.R.; Gourley, S.L. Involvement of the rodent prelimbic and medial orbitofrontal cortices in goal-directed action: A brief review. J. Neurosci. Res. 2020, 98, 1020-1030. [CrossRef]

51. Li, W.; Wang, Y.; Ward, B.D.; Antuono, P.G.; Li, S.J.; Goveas, J.S. Intrinsic inter-network brain dysfunction correlates with symptom dimensions in late-life depression. J. Psychiatr. Res. 2017, 87, 71-80. [CrossRef] [PubMed]

52. Hermans, E.J.; Henckens, M.J.; Joels, M.; Fernandez, G. Dynamic adaptation of large-scale brain networks in response to acute stressors. Trends. Neurosci. 2014, 37, 304-314. [CrossRef] [PubMed]

53. Seeley, W.W. The Salience Network: A Neural System for Perceiving and Responding to Homeostatic Demands. J. Neurosci. 2019, 39, 9878-9882. [CrossRef] [PubMed]

54. Kim, J.; Kim, Y.K. Crosstalk between Depression and Dementia with Resting-State fMRI Studies and Its Relationship with Cognitive Functioning. Biomedicines 2021, 9, 82. [CrossRef]

55. Menon, V. Large-scale brain networks and psychopathology: A unifying triple network model. Trends. Cogn. Sci. 2011, 15, 483-506. [CrossRef]

56. Peters, S.K.; Dunlop, K.; Downar, J. Cortico-Striatal-Thalamic Loop Circuits of the Salience Network: A Central Pathway in Psychiatric Disease and Treatment. Front. Syst. Neurosci. 2016, 10, 104. [CrossRef]

57. Laubach, M.; Amarante, L.M.; Swanson, K.; White, S.R. What, If Anything, Is Rodent Prefrontal Cortex? eNeuro 2018, 5. [CrossRef]

58. Chand, G.B.; Wu, J.; Hajjar, I.; Qiu, D. Interactions of the Salience Network and Its Subsystems with the Default-Mode and the Central-Executive Networks in Normal Aging and Mild Cognitive Impairment. Brain. Connect. 2017, 7, 401-412. [CrossRef]

59. Putcha, D.; Ross, R.S.; Cronin-Golomb, A.; Janes, A.C.; Stern, C.E. Salience and Default Mode Network Coupling Predicts Cognition in Aging and Parkinson's Disease. J. Int. Neuropsychol. Soc. 2016, 22, 205-215. [CrossRef]

60. van Leeuwen, J.M.C.; Vinkers, C.H.; Vink, M.; Kahn, R.S.; Joels, M.; Hermans, E.J. Disrupted upregulation of salience network connectivity during acute stress in siblings of schizophrenia patients. Psychol. Med. 2021, 51, 1038-1048. [CrossRef]

61. Tsvetanov, K.A.; Henson, R.N.; Tyler, L.K.; Razi, A.; Geerligs, L.; Ham, T.E.; Rowe, J.B.; Cambridge Centre for Ageing and Neuroscience. Extrinsic and Intrinsic Brain Network Connectivity Maintains Cognition across the Lifespan Despite Accelerated Decay of Regional Brain Activation. J. Neurosci. 2016, 36, 3115-3126. [CrossRef] [PubMed]

62. Santarnecchi, E.; Sprugnoli, G.; Tatti, E.; Mencarelli, L.; Neri, F.; Momi, D.; Di Lorenzo, G.; Pascual-Leone, A.; Rossi, S.; Rossi, A Brain functional connectivity correlates of coping styles. Cogn. Affect. Behav. Neurosci. 2018, 18, 495-508. [CrossRef] [PubMed]

63. Ewers, M.; Luan, Y.; Frontzkowski, L.; Neitzel, J.; Rubinski, A.; Dichgans, M.; Hassenstab, J.; Gordon, B.A.; Chhatwal, J.P.; Levin, J.; et al. Segregation of functional networks is associated with cognitive resilience in Alzheimer's disease. Brain 2021, 144, 2176-2185. [CrossRef] [PubMed]

64. Ewers, M. Reserve in Alzheimer's disease: Update on the concept, functional mechanisms and sex differences. Curr. Opin. Psychiatry 2020, 33, 178-184. [CrossRef] [PubMed]

65. Serra, L.; Mancini, M.; Cercignani, M.; Di Domenico, C.; Spano, B.; Giulietti, G.; Koch, G.; Marra, C.; Bozzali, M. Network-Based Substrate of Cognitive Reserve in Alzheimer's Disease. J. Alzheimers Dis. 2017, 55, 421-430. [CrossRef] [PubMed]

66. Sun, F.W.; Stepanovic, M.R.; Andreano, J.; Barrett, L.F.; Touroutoglou, A.; Dickerson, B.C. Youthful Brains in Older Adults: Preserved Neuroanatomy in the Default Mode and Salience Networks Contributes to Youthful Memory in Superaging. J. Neurosci. 2016, 36, 9659-9668. [CrossRef]

67. Conti, L.; Riccitelli, G.C.; Preziosa, P.; Vizzino, C.; Marchesi, O.; Rocca, M.A.; Filippi, M. Effect of cognitive reserve on structural and functional MRI measures in healthy subjects: A multiparametric assessment. J. Neurol. 2021, 268, 1780-1791. [CrossRef]

68. Bahtiyar, S.; Gulmez Karaca, K.; Henckens, M.; Roozendaal, B. Norepinephrine and glucocorticoid effects on the brain mechanisms underlying memory accuracy and generalization. Mol. Cell Neurosci. 2020, 108, 103537. [CrossRef]

69. de Kloet, E.R.; de Kloet, S.F.; de Kloet, C.S.; de Kloet, A.D. Top-down and bottom-up control of stress-coping. J. Neuroendocrinol. 2019, 31, e12675. [CrossRef]

70. Liang, F.; Xu, Q.; Jiang, M.; Feng, R.; Jiang, S.; Yuan, B.; Xu, S.; Wu, T.; Wang, F.; Huang, J.H. Emotion Induced Monoamine Neuromodulator Release Affects Functional Neurological Disorders. Front. Cell Dev. Biol. 2021, 9, 633048. [CrossRef]

71. Puglisi-Allegra, S.; Andolina, D. Serotonin and stress coping. Behav. Brain. Res. 2015, 277, 58-67. [CrossRef] [PubMed]

72. de Boer, S.F.; Buwalda, B.; Koolhaas, J.M. Untangling the neurobiology of coping styles in rodents: Towards neural mechanisms underlying individual differences in disease susceptibility. Neurosci. Biobehav. Rev. 2017, 74, 401-422. [CrossRef] [PubMed] 
73. Maier, S.F.; Watkins, L.R. Stressor controllability and learned helplessness: The roles of the dorsal raphe nucleus, serotonin, and corticotropin-releasing factor. Neurosci. Biobehav. Rev. 2005, 29, 829-841. [CrossRef] [PubMed]

74. Haber, S.N.; Fudge, J.L.; McFarland, N.R. Striatonigrostriatal pathways in primates form an ascending spiral from the shell to the dorsolateral striatum. J. Neurosci. 2000, 20, 2369-2382. [CrossRef]

75. Stevenson, C.W.; Sullivan, R.M.; Gratton, A. Effects of basolateral amygdala dopamine depletion on the nucleus accumbens and medial prefrontal cortical dopamine responses to stress. Neuroscience 2003, 116, 285-293. [CrossRef]

76. Bland, S.T.; Hargrave, D.; Pepin, J.L.; Amat, J.; Watkins, L.R.; Maier, S.F. Stressor controllability modulates stress-induced dopamine and serotonin efflux and morphine-induced serotonin efflux in the medial prefrontal cortex. Neuropsychopharmacology 2003, 28, 1589-1596. [CrossRef]

77. Moghaddam, B. Stress activation of glutamate neurotransmission in the prefrontal cortex: Implications for dopamine-associated psychiatric disorders. Biol. Psychiatry 2002, 511, 775-787. [CrossRef]

78. Latagliata, E.C.; Valzania, A.; Pascucci, T.; Campus, P.; Cabib, S.; Puglisi-Allegra, S. Stress-induced activation of ventral tegmental mu-opioid receptors reduces accumbens dopamine tone by enhancing dopamine transmission in the medial pre-frontal cortex. Psychopharmacology 2014, 231, 4099-4108. [CrossRef]

79. Fiore, V.G.; Mannella, F.; Mirolli, M.; Latagliata, E.C.; Valzania, A.; Cabib, S.; Dolan, R.J.; Puglisi-Allegra, S.; Baldassarre, G Corticolimbic catecholamines in stress: A computational model of the appraisal of controllability. Brain. Struct. Funct. 2015, 220, 1339-1353. [CrossRef]

80. Nicniocaill, B.; Gratton, A. Medial prefrontal cortical alpha1 adrenoreceptor modulation of the nucleus accumbens dopamine response to stress in Long-Evans rats. Psychopharmacology 2007, 191, 835-842. [CrossRef]

81. Doherty, M.D.; Gratton, A. Medial prefrontal cortical D1 receptor modulation of the meso-accumbens dopamine response to stress: An electrochemical study in freely-behaving rats. Brain. Res. 1996, 715, 86-97. [CrossRef]

82. Lloyd, K.; Dayan, P. Safety out of control: Dopamine and defence. Behav. Brain. Funct. 2016, 12, 15. [CrossRef] [PubMed]

83. Cools, R.; D'Esposito, M. Inverted-U-shaped dopamine actions on human working memory and cognitive control. Biol. Psychiatry 2011, 69, e113-e125. [CrossRef] [PubMed]

84. Balleine, B.W.; O'Doherty, J.P. Human and rodent homologies in action control: Corticostriatal determinants of goal-directed and habitual action. Neuropsychopharmacology 2010, 35, 48-69. [CrossRef] [PubMed]

85. Clark, P.J.; Amat, J.; McConnell, S.O.; Ghasem, P.R.; Greenwood, B.N.; Maier, S.F.; Fleshner, M. Running Reduces Uncontrollable Stress-Evoked Serotonin and Potentiates Stress-Evoked Dopamine Concentrations in the Rat Dorsal Striatum. PLoS ONE 2015, 10, e0141898. [CrossRef]

86. Giorgi, O.; Lecca, D.; Piras, G.; Driscoll, P.; Corda, M.G. Dissociation between mesocortical dopamine release and fear-related behaviours in two psychogenetically selected lines of rats that differ in coping strategies to aversive conditions. Eur. J. Neurosci. 2003, 17, 2716-2726. [CrossRef]

87. Friedman, A.; Homma, D.; Gibb, L.G.; Amemori, K.; Rubin, S.J.; Hood, A.S.; Riad, M.H.; Graybiel, A.M. A Corticostriatal Path Targeting Striosomes Controls Decision-Making under Conflict. Cell 2015, 161, 1320-1333. [CrossRef]

88. Chen, X.; Jiang, Y.; Wang, J.; Liu, Y.; Xiao, M.; Song, C.; Bai, Y.; Yinuo Han, N.; Han, F. Synapse impairment associated with enhanced apoptosis in post-traumatic stress disorder. Synapse 2020, 74, e22134. [CrossRef]

89. Friedman, A.; Homma, D.; Bloem, B.; Gibb, L.G.; Amemori, K.I.; Hu, D.; Delcasso, S.; Truong, T.F.; Yang, J.; Hood, A.S.; et al. Chronic Stress Alters Striosome-Circuit Dynamics, Leading to Aberrant Decision-Making. Cell 2017, 171, 1191-1205.e1128. [CrossRef]

90. Runge, K.; Cardoso, C.; de Chevigny, A. Dendritic Spine Plasticity: Function and Mechanisms. Front. Synaptic. Neurosci. 2020, 12, 36. [CrossRef]

91. Qiao, H.; Li, M.X.; Xu, C.; Chen, H.B.; An, S.C.; Ma, X.M. Dendritic Spines in Depression: What We Learned from Animal Models. Neural. Plast. 2016, 2016, 8056370. [CrossRef] [PubMed]

92. Witzig, V.S.; Komnig, D.; Falkenburger, B.H. Changes in Striatal Medium Spiny Neuron Morphology Resulting from Dopamine Depletion Are Reversible. Cells 2020, 9, 2441. [CrossRef] [PubMed]

93. Conio, B.; Martino, M.; Magioncalda, P.; Escelsior, A.; Inglese, M.; Amore, M.; Northoff, G. Opposite effects of dopamine and serotonin on resting-state networks: Review and implications for psychiatric disorders. Mol. Psychiatry 2020, 25, 82-93. [CrossRef] [PubMed]

94. McCutcheon, R.A.; Nour, M.M.; Dahoun, T.; Jauhar, S.; Pepper, F.; Expert, P.; Veronese, M.; Adams, R.A.; Turkheimer, F.; Mehta, M.A.; et al. Mesolimbic Dopamine Function Is Related to Salience Network Connectivity: An Integrative Positron Emission Tomography and Magnetic Resonance Study. Biol. Psychiatry 2019, 85, 368-378. [CrossRef] [PubMed]

95. Palaniyappan, L.; Liddle, P.F. Does the salience network play a cardinal role in psychosis? An emerging hypothesis of insular dysfunction. J. Psychiatry Neurosci. 2012, 37, 17-27. [CrossRef]

96. Li, J.; Curley, W.H.; Guerin, B.; Dougherty, D.D.; Dalca, A.V.; Fischl, B.; Horn, A.; Edlow, B.L. Mapping the subcortical connectivity of the human default mode network. Neuroimage 2021, 245, 118758. [CrossRef]

97. Decourt, M.; Jimenez-Urbieta, H.; Benoit-Marand, M.; Fernagut, P.O. Neuropsychiatric and Cognitive Deficits in Parkinson's Disease and Their Modeling in Rodents. Biomedicines 2021, 9, 684. [CrossRef] 
98. Theis, H.; Probst, C.; Fernagut, P.O.; van Eimeren, T. Unlucky punches: The vulnerability-stress model for the development of impulse control disorders in Parkinson's disease. NPJ Park. Dis. 2021, 7, 112. [CrossRef]

99. Christopher, L.; Marras, C.; Duff-Canning, S.; Koshimori, Y.; Chen, R.; Boileau, I.; Segura, B.; Monchi, O.; Lang, A.E.; Rusjan, P.; et al. Combined insular and striatal dopamine dysfunction are associated with executive deficits in Parkinson's disease with mild cognitive impairment. Brain 2014, 137, 565-575. [CrossRef] 